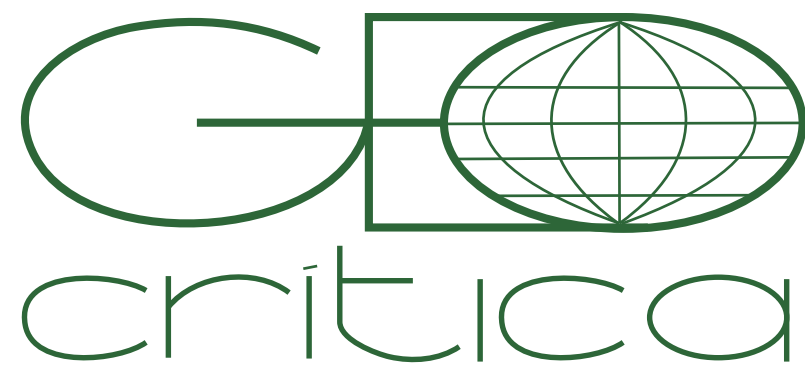

\section{Scripta Nova}

Revista Electrónica de Geografía y Ciencias Sociales

Universitat de Barcelona

ISSN: 1138-97

Vol. 25, Núm. 4 (2021), p. 73-96

\title{
OS NOVÍSSIMOS MOVIMENTOS SOCIAIS E AS TERRITORIALIDADES POLÍTICAS JUVENIS: PERTENCER, EXISTIR E RESISTIR!
}

\author{
Lara Pires Weissbock \\ Universidade Estadual do Centro Oeste (UNICENTRO) \\ prof.larapires@gmail.com \\ Màrcia da Silva \\ Universidade Estadual do Centro Oeste (UNICENTRO) \\ marcia.silvams@gmail.com
}

Recibido: 23 de julio 2020; Revisado: 21 de mayo 2021; Aceptado: 21 de octubre 2021

\section{Os novíssimos movimentos sociais e as territorialidades políticas juvenis: pertencer, existir e resistir! (Resumo)}

As transformações nos processos globais foram e são acompanhadas por distintas lutas sociais que têm como princípio básico a busca por reverter ou fazer frente à lógica hegemônica, as quais passaram a ocorrer de forma distinta a partir de 2010. Para tanto, investigamos sobre as territorialidades políticas juvenis, partindo da compreensão de que nos novíssimos movimentos sociais há uma intersecção e articulação entre as mobilizações que acontecem nos espaços online e nos físicos. Discute-se ainda sobre jovens, Geração \# e Blockchain, bem como trabalhos de campo no movimento feminista em Barcelona e no Brasil, por questionários online e de entrevistas no Brasil em 2019. Pudemos induzir que a territorialidade política dos jovens está no movimento do lado vivido e atuante do poder/contrapoder, capturando o oculto nas relações entre sociedade, espaço, poder e indivíduos, nas suas individualidades e/ou coletividades. As suas territorialidades políticas está em pertencer, existir e resistir!

Palavras-chave: territorialidade política; jovens; Geração \# e Blockchain; novíssimos movimentos sociais.

The new social movements and as youth political territorialities: belong, exist and resist!(Abstract)

The transformations in the global processes were and are accompanied by different social struggles that have as a basic principle the search for reversing or facing the hegemonic logic, which started to occur in a different way from 2010. To do so, we investigated the youth political territorialities, starting from the understanding that in the newest social movements there is an intersection and articulation between the mobilizations that take place in online and physical spaces. It is also discussed about young people, Generation \# and Blockchain, as well as fieldwork in the feminist movement in Barcelona and Brazil, through online questionnaires and interviews in Brazil in 2019. We could infer that the political territoriality of young people is on the side movement lived and active of power/counterpower, capturing the hidden in the relations between society, space, power and individuals, in their individualities and / or collectivities. Their political territorialities are in belonging, existing and resisting!

Keywords: political territoriality; young; Generation \# and Blockchain; new new social movements. 
Desde o final de 2010 e início de 2011 temos vivenciado um ciclo internacional de mobilizações distintas das até então ocorridas, em especial quanto às agendas e as formas de ação, e que compartilham reivindicações que partem de uma forte crise de legitimidade dos agentes políticos, além do descontentamento generalizado face à crise econômica, social, política e cultural.

Passaram a emergir movimentos sociais anti ou alterglobalização, transnacionais e articulados em redes, o que nos instigou a analisar alguns aspectos destes, incitadas, inclusive, por desvelar o motivo que levam estudiosos a indicar que há distinções nos ocorridos a partir do final de 2010, em especial pela forma com que emergem e ocorrem, os chamados novíssimos movimentos sociais. Além disso, refletir se é possível afirmar que há uma territorialidade política, em especial dos jovens por nós investigados nos trabalhos de campo.

Para tanto, trataremos sobre o conceito de novíssimos movimentos sociais, jovens, Gerações \# e Blockchain, e territorialidade, tendo como base empírica e observações territoriais a realização dos trabalhos de campo em Barcelona e no Brasil em 2019.

Versando sobre os procedimentos de escolha e origens dos jovens que participaram desta pesquisa, destacaremos o acompanhamento das ações da participação do movimento feminista em Barcelona, o 8M, no ano de 201911, da aplicação de questionários online com jovens que participaram deste movimento em Barcelona (tendo respondentes de distintas partes da Espanha) e no Brasil, e entrevistas no Brasil.

Optamos por questionário semiestruturado, e sua aplicação iniciou-se no dia 12 de março de 2019 em Barcelona, difundido inicialmente para contatos realizados no movimento pelas ruas de Barcelona em 8 de março de 2019. Em uma semana foram respondidos 88 questionários (no entanto, considera-se 80 válidos, uma vez que este é o público que se enquadra nas discussões sobre Geração).

Na semana seguinte foi realizada a aplicação de questionários no Brasil, em que a divulgação se deu através de redes sociais particulares sem um contato direto com os respondentes. Foram respondidos 47 questionários também no período de uma semana, no entanto, considerados válidos apenas 35 , pelos mesmos motivos que o anterior.

Também foram realizadas entrevistas ${ }^{2}$ com $8^{3}$ jovens no Brasil, escolhidos à medida que participávamos de movimentos sociais e de eventos de coletivos juvenis, de 2017 a 2020, em que ocorriam conversas informais com aqueles que ali estavam. E isso no sentido de levantar informações sobre quem eram, suas trajetórias nos movimentos sociais, em coletivos e/ou partidos políticos, etc.

\footnotetext{
1 Pesquisa realizada durante a instância em Barcelona pelo Programa de Doutorado Sanduíche no Exterior, com bolsa concedida pela Coordenação de Aperfeiçoamento de Pessoal de Nível Superior, sob norientação do professor Doutor Carles Feixa, da Universitat Pompeu Fabra.
}

2 As entrevistas foram realizadas entre setembro a novembro de 2019.

3 Em um universo de trinta e dois jovens que já tinham aceitado participar, mas não o fizeram. 
Quanto aos entrevistados, o contato com 6 jovens ${ }^{4}$ foi realizado de forma direta por nós (MJE1, MJE2, MJE3, MJE4, MJE5 e HJE1), um jovem indicado pelo entrevistado HJEl e um jovem indicado pelo HJE2.

Sobre a forma com que estes jovens foram contatados, a MJEl foi por meio de uma rede social, depois que se teve acesso a um documentário, Espero a tua (re)volta ${ }^{5}$, sob a direção de Eliza Capai, que trata sobre as manifestações estudantis em 2015 no Brasil. A MJEl consta na ficha de atores que participaram do referido documentário. Da mesma forma, a MJ3 foi contatada via rede social.

A MJE2 é uma figura pública em movimentos sociais juvenis e também foi contatada inicialmente pela internet. O contato pessoal foi realizado no $47^{\circ}$ Congresso da União Paranaense dos Estudantes (CONUPE $\left.{ }^{6}\right)$.

O contato com a MJE4 também foi realizado durante o $47^{\circ}$ CONUPE, a qual estava se candidatando, naquele momento, à presidente da União Brasileira dos Estudantes Secundaristas do Paraná. No mesmo evento foi realizado o contato com a MJE5.

O HJEl foi contatado inicialmente no evento Acampamento Internacional das Juventudes em Luta ${ }^{7}$, em 2017 e no $47^{\circ}$ CONUPE, em 2019, momento em que se passou a ter o contato do HJE3, jovem contatado presencialmente na Greve Geral pela Educação em Recife/Pernambuco/Brasil.

Tendo tratado das questões estruturais no que tange a organização do artigo tanto metodológica quanto teoricamente, que se configura como parte dos resultados obtidos em pesquisa de doutorado defendida em 2021 e intitulada PERTENÇO, LOGO EXISTO E RESISTO! As territorialidades políticas juvenis nos novíssimos movimentos sociais, partimos a discussões sobre os novíssimos movimentos sociais.

\section{A teoria dos novíssimos movimentos sociais para discutir as mobilizações juvenis}

Para Castells (2018), no que tange o estudo sobre os movimentos sociais é importante nos atentarmos com o que propõe à análise sobre globalização, informacionalização e movimentos sociais. Sobre este último, o autor considera que devem ser compreendidos em seus próprios termos, ou seja, "[...] eles são o que dizem ser" (Castells 2018, 124). As práticas dos movimentos sociais, entre elas as discursivas, são a sua autodefinição.

\footnotetext{
4 Nos referiremos a eles, respeitando suas identidades, como MJQEs 1 - mulher jovem 1 respondente do questionário da Espanha, HJQEsl - homem jovem 1 respondente do questionário na Espanha, MJQBrl mulher jovem 1 respondente do questionário no Brasil e assim sucessivamente. Quando nos referirmos aos entrevistados estarão como MJE1 - mulher jovem 1 entrevistada e assim sucessivamente.
}

5 Um retrato do movimento estudantil que ganhou força a partir do ano de 2015 ocupando escolas estaduais por todo Brasil. O documentário foi o vencedor do Amnesty International Film Prize e do Peace Film Prize do Festival de Berlim.

6 Evento no qual participamos, no Brasil em 2019.

7 Evento no qual participamos, no Brasil em 2017. 
No entanto, há que se considerar que, e concordando com Castells (2018), que esta perspectiva nos afasta da presunção de interpretar a "verdadeira" consciência dos movimentos sociais, como se sua existência estivesse apenas diretamente atrelada à revelação de contradições estruturais "reais". Ou que, para existir, houvesse a necessidade de carregar essas contradições de maneira igual como fazem com suas bandeiras e armas, por exemplo.

Ao partir destes pressupostos, considera-se importante que haja uma linha de pesquisa que consista em estabelecer a relação entre os diversos movimentos, conforme deliberados por suas práticas, valores e discursos, e os processos sociais aos quais semelham estar associados como, por exemplo, a globalização, a informacionalização, a crise da democracia representativa e predominância da política simbólica no espaço da mídia.

E, em segundo lugar, "os movimentos sociais podem ser conservadores, revolucionários, ambas as coisas, ou nenhuma delas" (Castells 2018, 125). Portanto, do ponto de vista analítico, não há movimentos sociais "bons" ou "maus", mas todos são sintomas de nossas sociedades e, portanto, todos acarretam impactos nas estruturas sociais, em distintos graus de intensidade, provocando resultados diferentes e que devem ser motivados por meio de pesquisas.

Partimos do princípio, e concordando com Castells $(2018,125)$, que “[...] todos representam indícios significativos de novos conflitos sociais, germes de resistência social e, em alguns casos, de transformação social".

Segundo Reguillo (2017), a partir de 2010 os protestos se intensificaram e no que diz respeito às causas e aos desconfortos que organizaram e organizam esses protestos, podem ser classificados em quatro grandes grupos. Por primeiro, aqueles que se articulam em torno da "justiça econômica", em alusão à pobreza e à desigualdade, assim como às críticas as reformas fiscais e energéticas que comprometem a vida das maiorias.

Um segundo grupo, os vinculados aos problemas relacionados à representação e crise política, com temáticas relacionadas às críticas à democracia e seus problemas de corrupção.

Em terceiro, de protestos que se enquadram na "justiça global", permeados por questões que proclamam resistência e discordância contra os organismos reguladores internacionais, a que exemplifica como o Fundo Monetário Internacional e/ou acordos de livre comércio. Aqui também cabem aqueles que reivindicam conteúdos relacionados à situação ambiental, bem como a interferência de empresas nos recursos nacionais.

E, por fim, um quarto grupo, relacionados aos direitos humanos, de liberdade e também ao direito às questões comuns, como direitos sexuais, digitais, ambientais, etc.

Neste rol de movimentos sociais, abrangem reivindicações que ensejam transformações sociais, ou seja, estão em rejeição ao status quo, sendo importante compreendê-los enquanto lutas que atuam em redes sociopolíticas e culturais, de maneiras diversificadas como, por exemplo, via fóruns, plenárias, colegiados, conselhos etc. Lutas essas que acabam por ser responsáveis por articulações de movimentos nas mais distintas escalas e espaços, desde o local ao transnacional, internacionalizando-se 
rapidamente e com distintas temáticas que acabam por criar novas agendas e propostas (Gohn 2018).

Portanto, são mais "[...] plurais, autônomas e horizontais, características distantes das estruturas institucionalizadas." (Perez e Souza 2017, 10), o que, na teoria dos movimentos sociais, tem sido tratado por novíssimos movimentos sociais.

De antemão, considera-se importante, antes de adentrar em especificidades do que se compreende por novíssimos movimentos sociais, uma breve apresentação do que são os novos movimentos sociais, os quais os antecedem.

Os novos movimentos sociais (originários de paradigmas europeus de estudo dos movimentos sociais) foram tratados como uma reação às transformações estruturais nas sociedades capitalistas ocidentais, tendo sido estudados, principalmente, os movimentos sociais das mulheres, dos ambientalistas, dos estudantes e da paz. Asseverava-se que as características básicas dos novos movimentos sociais eram cinco:

[...] seus valores - usualmente antimodernistas -, as formas de ação - com o uso intensivo de formas não-convencionais -, sua constituição - com grupos predispostos a participar porque são marginalizados pelo status-quo vigente ou porque se tornaram sensíveis aos resultados societais da modernização capitalista, as novas aspirações e a satisfação de necessidades postas em risco pelas exigências da burocratização e aumento da industrialização - levando à perda de laços tradicionais e das estruturas de lealdade existentes (Gohn 1997, 82).

E a implicação de tudo isso teve como objetivo levar as pessoas a estarem mais receptivas às novas visões utópicas sociais, protagonizadas pelos chamados "novos atores".

Outros elementos constitutivos dos chamados novos movimentos sociais fazem referência ao fato de não serem motivados por questões redistributivas, mas sim, empenhados em uma luta simbólica que está em torno de definições da boa vida. Portanto, são formas de resistência à colonização do mundo, assim como reações à padronização, racionalização das influências mútuas sociais e em favor da manutenção ou ampliação de estruturas comunicativas, reivindicando a qualidade de vida, igualdade, realização pessoal, participação e direitos humanos (Alonso 2009, 62).

Para o autor, estes podem ser compreendidos como formas particulares de resistência e reativos aos rumos do desenvolvimento socioeconômico que buscam a reapropriação tanto de tempo, espaço, quanto de relações do cotidiano. E, para além, são contestações pós-materialistas, "com motivações de ordem simbólica e voltadas para a construção ou o reconhecimento de identidades coletivas" (Alonso 2009, 64).

Posto isto, em um contexto de crise econômica a nível global em 2008, há o surgimento de um novo ciclo global de mobilizações, com características distintas das até então vividas. Para Álvarez-Benavides (2016), este está enquanto um marco no que diz respeito a forma com que passaram a ocorrer, em que estiveram inevitavelmente arrolados, entrelaçados com propósitos e em contextos distintos, mas com certas similaridades que nos fazem falar de uma mudança real. 
Betancor e Cilleros $\left(2013,248-249\right.$, tradução nossa $\left.{ }^{8}\right)$, perceberam que os movimentos e protestos sociais dos últimos anos, sob o efeito, inclusive, de devastadoras condições de trabalho, "[...] produziram mudanças significativas nas expressões do conflito social contemporâneo, bem como novidades nas formas de mobilização social, que cresceram quase proporcionalmente".

E, nesse contexto, passa a haver uma forma distinta de mobilizar-se, em que estudos que partem inicialmente da Europa e Estados Unidos, têm tratado os movimentos sociais a partir da chamada teoria dos novíssimos movimentos sociais, que se organizam, em especial, a partir da internet, mas também configurando-se por diversas organizações de forma local em espaços físicos.

Do mesmo modo que os novos movimentos sociais, os repertórios de ação dos novíssimos movimentos sociais, incluem manifestações em espaços físicos, mas as chamadas à ação se dão através da internet e a mobilização se dá no espaço virtual.

Caracterizam-se também por serem considerados com caráter mais autônomo e horizontal, marcadamente dinamizados pelos jovens, as lutas sociais se internacionalizam de forma rápida, abrangem uma diversa gama temática e seu poder vai para além da mobilização.

Concordando com Juris, Pereira e Feixa (2012), os novíssimos movimentos sociais são os que ocorrem na fronteira entre o espaço físico e o virtual. Enfatizam as transformações e também os conflitos sociais integrados à consolidação do capitalismo informacional.

A base social desses movimentos abrange gerações, gêneros, etnias, territórios e a sua base espacial está localizada em um espaço globalmente entrelaçado, como o sistema neoliberal a que esses movimentos se opõem (Juris, Pereira e Feixa 2012). E essas questões são essenciais para tentar caracterizar, mapear, dar forma aos movimentos que se sucederam, em uma revolta interconectada que se baseia nos imaginários, utopias, dispositivos e tecnologias que milhões de jovens compartilham hoje.

Neste cenário, Reguillo (2017) questiona sobre quais são as características de todas essas mobilizações, porque geram o mais puro entusiasmo ou então as críticas e desqualificações mais extremas. Para ela, as respostas estão no fato de os novíssimos movimentos sociais serem de caráter aberto, não se limitando a nenhuma ideologia específica; por seu tom festivo, em que há espaço para todas e cada uma das indignações contrárias ao sistema; também por sua capacidade tecnológica, que transformou a internet em um aliado fundamental e em um espaço de viralização dinâmico; além disso, também se está diante de uma afeição em que participamos com outras e com outros, que é capaz de perfilhar o sofrimento que a distribuição desigual de bem-estar nos inflige e inflige a outras pessoas. Estamos indignados, zangados, e somos sujeitos que veem e experimentam desigualdades.

Da mesma forma, eles têm como características comuns, independentemente de ser local ou global, o fato de se constituírem marcadamente dinamizados "[...] pelas

8 [...] inevitablemente relacionados, imbricados, con propósitos y en contextos diferentes, pero con ciertas similitudes que nos hacen hablar de un cambio real. 
camadas da juventude escolarizada, veiculadas através do ciberespaço, marcadas pela organização flexível, em rede, sem lideranças identificadas e, ainda, revelarem um caráter parcialmente espontâneo" (Estanque 2014, 66).

Ademais, as novas tecnologias, em especial a internet, são potenciais geradoras de mobilizações e formas de constituição e atuação de muitos grupos, em especial dos sujeitos das chamadas Geração \# e Geração Blockchain (Feixa 2014). A internet é recurso e fator estratégico porque seu poder está para além da mobilização, afetando o caráter da ação coletiva desenvolvida. Transformam-se em ações conectivas e o ambiente virtual ocupa lugar central no caráter dessas, em especial no que tange à infraestrutura de recursos para compor pautas, consensos, mobilizar a população, convocar, divulgar resultados de atos, agendas futuras etc. (Gohn 2018).

No entanto, mesmo que as tecnologias proporcionem a participação de vários protagonistas de maneira instantânea, não se pode afirmar que esse processo é de todo positivo por ter virtualidades, uma vez que mídias sociais interativas têm o poder de criar um espaço de apropriação da opinião pública para a constituição de consensos, por grupos de diferentes natureza e fins, e as consequências políticas disso (Gohn 2018).

É importante, a priori, compreender que a rede está em constante mudança e que é simultaneamente global e local, genérica e personalizada. Além disso, os movimentos sociais constituem-se enquanto contrapoder, o que significa dizer que contrapõem a premissa das relações de poder por ele compreendidas como constitutivas das sociedades, pois aqueles que detêm esse poder constituem as instituições conforme seus próprios interesses, exercido por meio da coerção e/ou ideologia. O contrapoder, portanto, caracteriza-se pela capacidade dos atores sociais reivindicarem seus próprios interesses (Castells 2013).

Ao analisar determinados movimentos sociais, devemos levar em consideração que não cabe colocá-los sob o mesmo plano, uma vez que, mesmo que os conteúdos reivindicatórios sejam os mesmos, há especificidades locais, sejam políticas, econômicas, culturais ou sociais que lhes trazem peculiaridades que devem ser analisadas, mesmo que se parta do pressuposto de que há componentes que os une e que tem como núcleo a insatisfação frente a uma ordem de coisas que já são percebidas como intoleráveis.

Exemplo disso são as reivindicações pelo aumento da democracia; a sociedade civil precarizada, em especial os jovens, com certo ceticismo com a ação institucional; a valorização da diversidade de expressão; o uso intensivo da internet; a preocupação com os mecanismos de gestão dos recursos; a impotência e frustração frente à experiência da violação de direitos humanos elementares, etc. (Soeiro 2014, Reguillo 2017).

Destes, podem ser indicados alguns movimentos sociais que abrangeram reivindicações que ensejavam essas transformações sociais, como a Primavera Árabe, que eclodiu em final de 2010 e em 2011 no Oriente Médio e no Norte da África; o Occupy Wall Street, movimento de protesto contra a desigualdade econômica e social, iniciado em 2011 na cidade de Nova York; o 15M, o chamado movimento dos Indignados, ocorrido em 15 de maio de 2011 na Espanha, iniciado em Madrid e depois difundindo-se por toda a Espanha. 
Em setembro de 2012 o movimento Que se Lixe a Troika, em Portugal; Todas las Mareas saíram às ruas com o lema "Marea ciudadana contra el golpe de los mercados" em fevereiro de 2013 na Espanha (as chamadas Mareas foram coletivos que surgiram do 15M, cada uma reivindicando um tema específico, como a educação, saúde etc.). Em 2017 o \#MeToo que impulsionou diversos movimentos feministas pelo mundo.

Além disso, no Brasil, as manifestações de junho de 2013, chamadas de diversas maneiras como \#VEMpraRUA, Outono Brasileiro, Movimento Passe Livre (MPL), etc., iniciadas, primeiramente, com o objetivo de reduzir a tarifa do transporte público. Logo as bandeiras passaram a se diversificar, exigindo para além da melhoria do transporte público, mas a serviços públicos em geral, contra a corrupção, etc.

No Brasil, em novembro de 2015, impulsionados pelas ondas de manifestações ocorridas no país e no mundo, estudantes Brasil afora encabeçaram protestos com o objetivo de denunciar o sucateamento da educação, buscando chamar a atenção da opinião pública, ocupando escolas e universidades. Este foi o movimento social chamado de Primavera Secundarista, que se manteve igualmente em 2016.

Também em 2016, ocorreram manifestações motivadas pelo processo de impeachment da então presidenta do Brasil, Dilma Rousseff, sob as hashtags que clamavam ao impeachment \#impeachmenent e \#foradilma, e aos que eram contrários \#naovaitergolpe e \#DilmaFica.

Em 2018 os protestos contra Jair Messias Bolsonaro, conhecidos como \#EleNão, liderados principalmente por mulheres e que ocorreram em diversas regiões do Brasil e do mundo, protestando contra a sua candidatura à presidência da República.

E, em 2019, ondas de protestos emergentes de políticas de governo do então presidente da república, Jair Messias Bolsonaro, como as ocorridas nos dias 15 de maio, 30 de maio e 13 de agosto de 2019, os chamados Tsunami da Educação; e também o Dia Nacional em Defesa da Educação, considerado como o primeiro grande protesto contrário ao governo, devido a cortes na educação, do ensino básico ao superior, e congelamentos nas áreas de desenvolvimento de ciência e tecnologia.

Nestas conjunturas, considera-se imprescindível refletir sobre quem são os sujeitos jovens que mobilizam-se, bem como a forma com que compreendem e interveem na configuração da sociedade em que estão inseridos.

Partindo da apreensão de uma construção histórica do conceito de jovem, o foco aqui está em analisá-los compreendendo-os no plural por conta da sua diversidade intrínseca, seja de classe social, etnia, gênero, dos espaços em que vivem e convivem, e a partir dos conceitos de Geração \# e Geração Blockchain, como segue.

\section{Gerações \# e Blockchain: os protagonistas dos novíssimos movimentos sociais}

Para Nilan e Feixa (2014), é importante compreendermos que não é possível fazer generalizações sobre o que é ser jovem na atualidade, uma vez que há uma diversidade 
intrínseca nestes sujeitos. E que a conexão entre hibridación ${ }^{9}$, mundos plurales $^{10}$ e globalización ${ }^{11}$ nos indica que na era da informação, as identidades geracionais estão cada vez mais localizadas, mas não são homogêneas.

Compreendem que entre os jovens de uma mesma geração existe um terreno comum, ao mesmo tempo em que a forma e o conteúdo dos produtos, das tendências e os movimentos desses grupos globais (no caso os jovens), se distinguem nas suas preferências culturais coletivas bem como em suas práticas, mas estes são amplamente sintetizados e implantados de várias maneiras, a nível local. Podemos exemplificar com a tendência hip hop, que está presente em diversos grupos jovens em todo o mundo, o que não significa que todos esses jovens comportem uma mesma cultura de hip hop (Nilan e Feixa 2014).

\begin{tabular}{|c|c|c|}
\hline DIMENSÃO & GERAÇÃO \# & GERAÇÃO BLOCKCHAIN \\
\hline Período & $\begin{array}{l}\text { Nascimento: } 1985-1995 \\
\text { Infância: } 1990 \mathrm{~s} \\
\text { Adolescência: } 2000 \mathrm{~s} \\
\text { Juventude: } 2010 \mathrm{~s}\end{array}$ & $\begin{array}{l}\text { Nascimento: } 1995-2005 \\
\text { Infância: } 2000 \mathrm{~s} \\
\text { Adolescência: } 2010 \mathrm{~s} \\
\text { Juventude: } 2020 \mathrm{~s}\end{array}$ \\
\hline Contexto & $\begin{array}{c}\text { Web } 2.0 \\
\text { Capitalismo em crise } \\
\text { Recessão }\end{array}$ & $\begin{array}{l}\text { Web } 3.0 \\
\text { Capitalismo pós-crise } \\
\text { Reconstrução }\end{array}$ \\
\hline Significante & $\begin{array}{c}\text { \# Hashtag: } \\
\text { medida numérica } \\
\text { América, s. XX } \\
\text { Conectividade }\end{array}$ & $\begin{array}{c}\text { Blockchain: } \\
\text { medida criptográfica } \\
\text { Internet, s. XXI } \\
\text { Interconexão }\end{array}$ \\
\hline Significado & $\begin{array}{l}\text { Hiperdigitalismo } \\
\text { Relocalização } \\
\text { Bisexualismo } \\
\text { Trending topics }\end{array}$ & $\begin{array}{c}\text { Pós-digitalismo } \\
\text { Deslocalização } \\
\text { Transexualismo } \\
\text { Fake News }\end{array}$ \\
\hline Características & $\begin{array}{c}\text { Geração \# } \\
\text { Espaço glocal } \\
\text { Tempo viral } \\
\text { Translocalismo } \\
\text { Rizoma }\end{array}$ & $\begin{array}{c}\text { Geração Blockchain } \\
\text { Não lugar } \\
\text { Slow Time } \\
\text { The Wall } \\
\text { Holograma }\end{array}$ \\
\hline Exemplos & $\begin{array}{c}\text { Cenas } \\
\text { Indignação } \\
\text { Microblogs } \\
\text { Tweenagers } \\
\text { Biografias Replicantes }\end{array}$ & $\begin{array}{l}\text { Microculturas } \\
\text { Nova Extrema Direita } \\
\text { Sharing Society } \\
\text { Emerging Adulthood } \\
\text { Biografias Cyborg }\end{array}$ \\
\hline
\end{tabular}

Quadro 1. Geração \# e Geração Blockchain

Fonte: Feixa e Weissböck (2019).

Elaboração: as autoras (2020).

Partindo deste pressuposto e ao buscar compreender os movimentos sociais contemporâneos para além dos acontecimentos mais visíveis, parte-se à reflexão sobre como buscamos entender os sujeitos que fizeram parte desta pesquisa.

9 Para saber mais: NILAN, Pam; Carles Feixa (2014).

10 Idem.

11 Idem. 
Além de nos propormos pensar sobre os jovens no plural e enquanto uma construção social que deve levar em consideração tanto as homogeneidades quanto as heterogeneidades, também nos referimos aos conceitos de geração (quadro 1), tratados por Feixa (2014). E isso, com o objetivo de pensar as formas com que esses jovens se organizam nos chamados novíssimos movimentos sociais.

Mapeando o perfil dos jovens desta pesquisa, é possível vislumbrar que tanto dos que responderam ao questionário na Espanha (por contatos realizados no $8 \mathrm{M}$ em Barcelona) quanto os que responderam no Brasil, pelos questionários e entrevistas, que se enquadram no que tratamos de Geração \# e Geração Bockchain, em que temos a seguinte caracterização ( quadro 2):

Levando em consideração as suas idades, relacionando ao quadro 2 que diz respeito aos conceitos de Geração \# e Blockchain, há aqueles que em suas adolescências estavam em um contexto da Web 2.0, com o capitalismo em crise, com a utilização da internet principalmente com significante de conectividade, o espaço se torna glocal e os movimentos sociais partem da indignação, característica principal das mobilizações ocorridas a partir de 2011 pelo mundo (Geração \#).

\begin{tabular}{|c|c|c|c|}
\hline $\begin{array}{l}\text { IDADE DOS JOVENS } \\
\text { PESOUISADOS }\end{array}$ & $\begin{array}{l}\text { QUESTIONÁRIO ONLINE } \\
\text { BARCELONA }\end{array}$ & $\begin{array}{l}\text { QUESTIONÁRIO ONLINE } \\
\text { BRASIL }\end{array}$ & ENTREVISTA BRASIL \\
\hline 14 & 1 Feminino & & \\
\hline 15 & 9 Feminino - 2 Masculino & & \\
\hline 16 & 14 Feminino - 9 Masculino & & 1 Feminino \\
\hline 17 & 16 Feminino - 10 Masculino & & 1 Masculino \\
\hline 18 & 1 Feminino - 5 Masculino & 6 Feminino & \\
\hline 19 & 1 Feminino & 1 Feminino - 1 Masculino & 1 Feminino \\
\hline 20 & 1 Feminino & 2 Feminino & \\
\hline 21 & 3 Feminino & 2 Feminino - 2 Masculino & 2 Feminino - 1 Masculino \\
\hline 22 & 1 Feminino & 1 Feminino - 1 Masculino & 1 Masculino \\
\hline 23 & & 1 Feminino - 1 Masculino & \\
\hline 24 & & 2 Feminino - 2 Masculino & \\
\hline 25 & & 1 Feminino & \\
\hline 26 & 1 Feminino - 1 Masculino & 1 Masculino & 1 Masculino \\
\hline 27 & 1 Feminino - 1 Masculino & 1 Masculino & \\
\hline 28 & 1 Masculino & 1 Feminino & \\
\hline 29 & 1 Feminino & 1 Feminino - 1 Masculino & \\
\hline 30 & 1 Feminino & 3 Feminino & \\
\hline 31 & & 1 Feminino - 1 Masculino & \\
\hline 33 & & 1 Feminino & \\
\hline 34 & & 1 Feminino & \\
\hline TOTAL & $\begin{array}{l}\text { SEXO FEMININO: } 50 \\
\text { SEXO MASCULINO: } 30\end{array}$ & $\begin{array}{l}\text { SEXO FEMININO: } 24 \\
\text { SEXO MASCULINO: } 11\end{array}$ & $\begin{array}{l}\text { SEXO FEMININO: } 5 \\
\text { SEXO MASCULINO: } 3\end{array}$ \\
\hline
\end{tabular}

Quadro 2. Idade e sexo dos jovens que participaram da pesquisa em Barcelona e no Brasil em 2019.

Elaboração: as autoras (2020). 
E aqueles que já nasceram em um contexto da Web 3.0, com a comunicação se dando por base na interconexão, em que os acontecimentos são (re)compartilhados quase que instantaneamente e o espaço passa a ser considerado como o não lugar ${ }^{12}$ (Geração Blockchain).

Além disso, reforçamos que devem ser compreendidos em suas diversidades, levando em consideração que é uma noção construída socialmente e, portanto, não cabe vislumbrar somente aspectos biológicos, mas pensar para além da faixa etária, imbuídas de temporalidades e transitoriedade de experiências, como é possível verificar em outras questões tratadas nas pesquisas de campo, que serão versadas na sequência.

Quando tratamos a respeito de fatores influenciadores e/ou determinantes na organização desses jovens à participação nos novíssimos movimentos sociais, dos 80 jovens que responderam ao questionário na Espanha, 65 não estavam vinculados a nenhuma instituição política, mas se mobilizaram a partir da escola e de suas redes de amizade. Assim como no questionário aplicado no Brasil, em que 29 dos 35 jovens pesquisados não faziam parte de nenhuma instituição política. E no caso das entrevistas com 8 jovens brasileiros, em 7 deles foi possível averiguar que as culturas parentais ${ }^{13}$, relacionadas às grandes redes culturais das quais fazem parte e que se referem as normas de conduta e valores vigentes no meio social de origem, seja a família, vizinhos, escola local, redes de amizades, entidades associativas, etc., foram determinantes em suas mobilizações, uma vez que uma das suas redes culturais decisivas foram as entidades associativas.

Considera-se que há que se partir do entendimento de que se por um lado as experiências individuais são distintas, por outro se tornam referências de uma temporalidade compartilhada globalmente. E captar estas contradições e paradoxos é parte fundamental para compreendermos sobre o ser jovem, a partir de suas experiências de vida e da apreensão dos fenômenos sociais em que eles estão envolvidos no presente.

Da pesquisa realizada na Espanha, um dos questionamentos foi como eles creem que as pessoas veem os jovens que participam dos movimentos sociais. Destes, 31 afirmaram que no imaginário das pessoas há uma visão tanto negativa quanto positiva, o que consideramos natural uma vez que este conceito é uma construção social e, portanto, os discursos implícitos no interior dos grupos dos quais fazem parte, da família, escola, mídia, etc., estão impregnados em seus imaginários, como pode ser verificado em suas respostas:

Às vezes eles são subestimados porque são jovens. Ser jovem está relacionado a não saber. Eu também acredito que a generalização dos jovens é frequente ${ }^{14}$ (MJQEs49);

12 O conceito de não lugar foi tratado na Geografia inicialmente por Marc Augé a partir de 1992, em que o autor afirma que "o não lugar é o espaço dos outros sem a presença dos outros, o espaço constituído em espetáculo" (Augé 1994, 167) e que estão como espaços não identitários, não históricos e não relacionais. No entanto, não trataremos sobre este conceito, apenas o mencionamos tendo por base os trabalhos de Feixa (2014) sobre gerações, mas sem intenção de discutir epistemologicamente a respeito.

13 Conceito tratado por Feixa (2006) referente às culturas juvenis, "Reloj de Arena".

14 A veces se les infravalora por el hecho de ser jóvenes. Ser joven lo relacionan con el no saber. También creo es la generalización de los jóvenes es frecuente. 
Depende da opinião que eles têm sobre a causa do movimento. Se eles são a favor do que é reivindicado, eles nos veem como combatentes e se não são a favor, suponho que eles tentem tirar nossa voz ${ }^{15}$ (MJQEs41); Muitas pessoas nos veem como se estivéssemos seguindo uma moda, "a moda do feminismo", outras dizem que queremos apenas fazer barulho ou que não entendemos essas coisas porque somos jovens demais. Mas sempre há pessoas que apoiam e veem que estamos interessados nesses movimentos sociais ${ }^{16}$ (MJQES61).

No entanto, em todos os momentos da mobilização bem como em outros questionamentos que lhes fizemos, os jovens se veem como uma geração que é capaz de tomar suas próprias decisões e que têm consciência de seus papéis na busca por mudanças.

Nas respostas de 23 jovens é possível verificar que em seus imaginários há uma generalização negativa do que é ser jovem, associando-os com questões tratadas por Schindler (1996), por exemplo, em que a juventude no século XVIII ainda estava impregnada de uma profunda ambivalência, que estava próxima à vida adulta, mas, no entanto, ainda não tinham as ações realizadas com a devida seriedade.

Assim como o tratado por Cassab (2011) quando discute sobre a concepção que se tinha a respeito do jovem e da juventude, em especial na transição do século XIX para o XX, associada a um período de emoções violentas, agressividade e instabilidade emocional, mesmo que na época a autora tenha se referido que esta imagem estava mais associada aos jovens operários.

E, de outro lado, 24 jovens compreendem que há uma visão positiva, tendo-lhes como sujeitos valentes e que se orgulham dessas gerações que lutam pela mudança, em corroboração com o que Keniston (2008) trata sobre a juventude, em que esta não é o mesmo que a adoção de causas, modas retóricas ou posturas juvenis, que normalmente estão associadas à negatividade:

Pelo que tenho podido perceber em algumas experiências ao longo da minha participação nesses movimentos, é que a maioria das pessoas veem os jovens com vontade de se mobilizar como uma esperança de melhoria no futuro e, geralmente, esses jovens recebem forte apoio e aceitação nos diferentes tecidos sociais ${ }^{17}$ (HJQEs 16); Jovens que querem mudar o mundo ${ }^{18}$ (MJQEs 15).

E 2 jovens afirmaram não saber responder esta questão.

15 Depende de la opinión que tengan sobre la causa del movimiento. Si están a favor de lo que se reivindica nos ven como personas luchadoras y si no están a favor supongo que tratan de quitarnos voz.

16 Mucha gente nos ven como si siguiéramos una moda, "la moda del feminismo", otros dicen que solo queremos hacer ruido, o que no entendemos de estas cosas porque somos demasiado jóvenes. Pero siempre hay gente que apoya y ve bien que estemos interesados en estos movimientos sociales.

17 Por lo que he podido percibir en algunas experiencias a lo largo de mi participación en estos movimientos es que la mayoría de personas ven a los jóvenes con ganas de movilizarse como una esperanza de mejora en el futuro y habitualmente estos jóvenes recogen un fuerte apoyo y aceptación en los diferentes tejidos sociales.

18 Jóvenes que quieren cambiar el mundo. 
A respeito da imagem que se têm sobre os jovens, nas entrevistas, as mesmas questões aparecem, como pode ser verificado nas afirmações da MJE3 que faz uma consideração que é pontuada em muitos momentos pelos que responderam a entrevista, quando indicam que participar ativamente de movimentos sociais modificaram e modificam suas concepções de mundo: "Acredito ser de grande valia para o crescimento deles, pois as vivências que eles terão nesses movimentos sociais auxiliarão muito para o crescimento do caráter deles."

Para a MJE5, "São jovens guerreiros! Inteligentes, que sabem muito bem pelo o que estão lutando! Jovens que se tornaram resistência em vários momentos! Jovens com vontade de um país melhor!".

Dos 35 questionários online aplicados no Brasil, 11 jovens afirmaram que existe dubiedade nas concepções que outras pessoas têm sobre eles: "De forma dividida, uns dizem que é rebeldia, extremismo, outros dizem que é preciso (MJQBr33); Depende. As experiências individuais interferem diretamente na interpretação das manifestações sociais. Há quem ache os jovens manifestantes revolucionários e há pessoas que o veem como vândalos" (MJQBr23).

Outros 18 jovens creem que a imagem que outras pessoas têm a respeito dos jovens que participam de movimentos sociais são negativas: "Como o jovem rebelde, que não está feliz com o que tem ao seu redor e muitas vezes posicionando-se politicamente com comentários agressivos (MJQBr32); Na maioria que a pessoa não tem o que fazer, por isso fica procurando algo diferente para fazer. Já os que não lutam é porque estão acomodados, e os jovens são o grupo de pessoas que está proporcionando-se, dispondose e lutando por algo diferente, não acatando ou aceitando "qualquer coisa da sociedade política", pois estamos em outro século, há mudanças, inovação e isso deve de vir para contribuir com desenvolvimento do ser humano, não a sua opressão" (MJQBr26).

E 3 jovens acreditam que a sociedade os veem com "bons olhos": Pessoas que lutam por seu futuro e pelas próximas gerações (HJQBr25); Acredito que as pessoas enxergam os jovens como atores do futuro que buscam um mundo melhor e lutam por isso (HJQBr21); Comprometidos e esclarecidos (MJQBr7). E 3 jovens afirmaram não saber responder a esta pergunta.

Inclusive estas questões, nos instigaram a buscar desvelar sobre as suas territorialidades políticas. Para tanto, discutiremos a respeito na sequência.

\section{Territorialidade política: o lado vivido do lado atuante do poder}

O objetivo de tratar a respeito de elementos que produzem e definem territorialidades, lançando o olhar sobre os novos objetos e arranjos que a contemporaneidade tem considerado no que diz respeito à organização e às dinâmicas socioespaciais, nos instigou a refletir sobre o que se trata por territorialidade em um contexto de mobilizações em espaços físicos e virtuais, considerando que um não anula o outro, mas que são relacionais entre eles. 
Para tanto, nos trabalhos de campo lhes questionamos, inclusive, sobre: se fazem parte de algum partido político e/ou coletivo; os principais conteúdos dos movimentos sociais dos quais participaram; o que os motivou e continua motivando a engajarem-se; o que consideram que tenha mudado na forma com que enxergam o mundo depois que passaram a participar de movimentos sociais; e o que eles diriam para si mesmos se pudessem voltar no início de sua militância.

Questões essas que acreditamos nos dar subsídios para pensar sobre a(s) territorialidade(s) particular(es), individual(is) e/ou coletiva(s) desses jovens, imersos em um contexto capaz de fornecer conexões que lhes permitem distintas possibilidades de mobilização, transcendendo o espaço físico à também um espaço virtual, e vice-versa.

Para tanto, as concepções que adotamos sobre territorialidade, vão ao encontro do que Sack (1986) discute, no sentido de que devemos conhecer não apenas o que a territorialidade é, mas o que ela produz. Assim, é na perspectiva relacional do espaço que a territorialidade se apresenta, ou seja, aproxima-se dos conceitos apresentados por Raffestin ( 1993), quando o autor afirma que o território não é tão somente o espaço físico, depósito material de recursos, mas é, sobretudo, o resultado de um programa intencional, isto é, da aplicação de energia e de informações para a implantação de estratégias adotadas por atores sintagmáticos que produzem este território e, por consequência, de territorialidade.

Da mesma forma que os autores acima, incluímos e concordamos com Yilmaz (2018, p. 133) ao apresentar a territorialidade como o oculto, a estrutura dissimulada do cotidiano e "[...] uma ação social, racional e propositalmente realizada por indivíduos e organizações coletivas". Posto isso, os movimentos sociais são aqui tratados enquanto resultantes de ações que desenvolvem relações complexas e diversificadas, sejam em seu interior ou no que está externo a eles.

Assim, a territorialidade é o "lado vivido" do "lado atuante" do poder (Raffestin 2012 ) e é nessa base que ela captura as interseções entre sociedade, espaço e poder. Na perspectiva de Sack (1986, p. 26) a "[...] territorialidade aponta para o fato de que as relações humanas no espaço não são neutras", mas embricadas de intencionalidade, construção social, estratégias e ações espaciais que configuram elementos-chave na tentativa de Sack (1986) em formular, categoricamente, uma teoria sobre a territorialidade, e a nós, em apresentar a mesma dinamicidade aos movimentos sociais, ou seja, também em suas territorialidades.

Sob estas perspectivas, os jovens quando indagados sobre o que lhes motivava a engajarem-se em movimentos sociais, nos trouxeram alguns desses elementos, indicando que acabaram por se influenciar, inclusive, a partir do meio no qual estavam inseridos, como é possível verificar nas entrevistas realizadas. A MJEl afirma que: “Criada em uma casa com dois comunistas filiados ao PCdoB, sempre estive presente nas atividades e quando tive a primeira oportunidade de me organizar, eu só fui", referindose às ocupações do Primavera Secundarista no Brasil. A MJE2 afirmou que participa de movimentos sociais de forma mais direta há 4 anos mais ou menos e que inicialmente o que lhe motivou foram as manifestações de 2015 (as Jornadas de Junho no Brasil e Primavera Secundarista) “[...] e o processo de golpe em 2016, de impeachment. Mas de 
fato o que me fez me engajar nas lutas dos movimentos sociais de uma maneira mais concreta foram as ocupações das escolas em 2016 contra a reforma do ensino médio e contra a PEC, na época, 241 e que depois passou a ser a PEC 55".

\title{
Para a MJE4:
}

Minhas motivações continuam basicamente as mesmas, lutar contra as enormes injustiças que esse sistema falido continua cometendo com as pessoas mais pobres, com as minorias, a falta de humanidade que nosso país se encontra me faz querer, todos os dias, mudar as coisas! O Brasil precisa de nós!

Da mesma forma o HJEl faz essas referências, trazendo um elemento que reforça as questões de associativismo a um determinado coletivo como algo representativo:

\begin{abstract}
Participo desde o meu penúltimo ano do ensino médio, fazem 7 anos. No início o que me motivou foi que minha mãe era professora e muito participativa. E na minha cidade tinha um movimento muito forte de agricultura familiar no qual me aproximei deles e foi ali que eu conheci a militância e as questões políticas de forma mais profunda. E o que continua me motivando é que a gente tem constantes ataques e se a luta não continuar a gente deixa os ataques nos avassalar, passarem por cima da gente. E a luta organizada, eu sou organizado na União da Juventude Comunista, ela me dá muito fôlego para isso. A luta organizada é o que garante a nossa unidade e o que garante que a gente tenha sempre um por que continuar lutando.
\end{abstract}

A menção ao associativismo enquanto algo que garante, na concepção do entrevistado, uma luta organizada, pode ser associado ao fato de a territorialidade possibilitar a promoção da cooperação entre indivíduos ou grupos. Além disso, que as relações de poder e, portanto, as territorialidades, são intencionais abarcando objetivos e metas, programas e planos, técnicas de saber e táticas de poder que precisam ser apreendidas, compreendidas, representadas e elucidadas como instantes e processualidades espaciais-territoriais. Tais práticas espacio-temporais-territoriais são processos históricos e geográficos de saber e poder, sujeição, aculturação, identificação, interação, exploração, mobilização, formação, etc. (Saquet 2015).

No que diz respeito aos conteúdos de reivindicação, estão relacionados diretamente com o contexto no qual vivem sob a lógica de uma cultura hegemônica que é reflexo da distribuição do poder cultural de uma forma escalar ampla, glocal.

O que pode ser observado na pesquisa realizada na Espanha, a partir dos questionários, quando aparecem de forma expressiva conteúdos reivindicatórios sobre a independência da Catalunha e a liberdade aos presos políticos, justificável pelo fato desses conteúdos terem sido motivadores de muitas mobilizações nos últimos anos na Espanha e que giram entorno de uma motivação central (figura 1): 


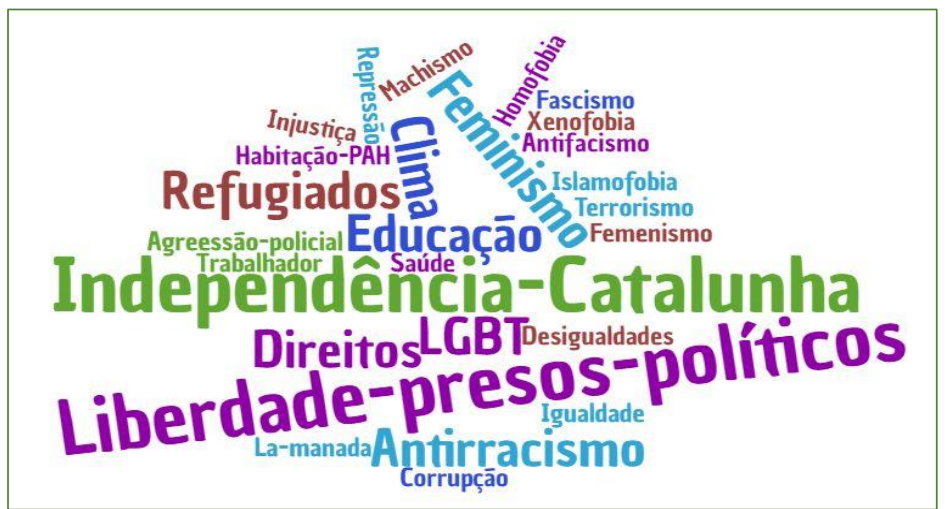

Figura 1. Conteúdos de reivindicação de movimentos sociais na Espanha.

Fonte: questionários online aplicado com jovens na Espanha no ano de 2019.

Elaboração: as autoras (2020).

No Brasil, os conteúdos de reivindicação também estão diretamente relacionados ao contexto do momento histórico, com grande ênfase a questões político-partidárias, inclusive (figura 2):

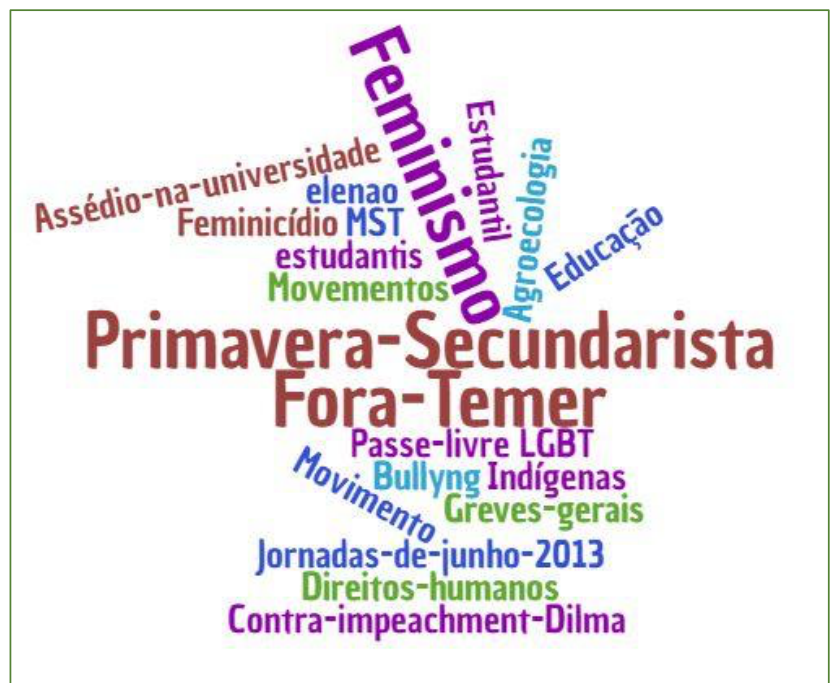

Figura 2. Conteúdos de reivindicação de movimentos sociais no Brasil.

Fonte: questionários online aplicado com jovens no Brasil no ano de 2019. Elaboração: as autoras (2020).

Para Yilmaz (2018), a morfologia territorial não pode ser explicada fora das atividades que a criaram e, no caso dos conteúdos reivindicatórios, estão diretamente relacionados aos tempos e aos espaços daqueles que os reivindicam.

Ademais, Koleni (2016) afirma que o poder dos movimentos sociais aumenta quando se relaciona com o interesse da maioria dos cidadãos e está fortemente correlacionado com os repertórios empregados pelos desafiantes sociais para conquistar 
atenção, o que inclui investigar o mecanismo pelo qual os movimentos sociais influenciam a opinião pública.

E expressa territorialidades quando estas se definem em distintas escalas espaciais, mudando no tempo por meio das relações de poder, das redes de circulação e comunicação, da dominação, identidades, entre outras afinidades sociais alcançadas entre sujeitos e entre estes com seu lugar de vida, seja econômica, política e culturalmente (Saquet e Sposito 2009).

Quando passamos a vislumbrar suas territorialidades políticas, é relevante compreendermos sobre suas trajetórias, buscando elementos identitários que os aproximem.

Indagamos-lhes sobre o associativismo à determinados coletivos e/ou partidos políticos, buscando verificar em que medida isso influenciou ou não, tanto as mobilizações específicas que investigamos, quanto em outras em que já tenham participado. Na Espanha, dos jovens com menos de 18 anos, 31 disseram que não fazem parte; 22 não fazem parte, mas seguem em redes sociais; e 8 participam de algum coletivo ou então são filiados a partidos. Dos com mais de 18 anos, 6 não participam; 6 acompanham nas redes sociais apenas; e 7 participam. No Brasil, 3 informaram que participam, mas não informaram o coletivo e/ou partido político; 3 informaram que são filiados a partidos políticos; 10 apenas seguem em redes sociais; e 19 não participam.

As justificativas são as mesmas: os que participam, o fazem por considerarem que apenas assim é possível lutar contra as questões que lhes levam a manifestar-se. E, aqueles que não participam diretamente, ou afirmam que não o fazem por "falta de tempo", "falta de interesse" ou então porque "não sabem como fazer para participar".

No entanto, nas entrevistas, o contrário pode ser constatado, mas consideramos que isso ocorreu pela forma com que os respondentes foram selecionados, que foi a partir de eventos organizados por determinados coletivos. Dos 8 entrevistados, 6 são filiados a algum partido político e/ou fazem parte de coletivos e 2 são autônomos. Daqueles que justificaram sua participação nestes, é possível verificar que nos seus imaginários apenas a partir desta vinculação é que uma luta tem bases sólidas e pode obter resultados mais efetivos. Aqui podemos retomar o que Raffestin (2012) trata por territorialidade, estando enquanto um conjunto das relações que as sociedades mantêm, através da assistência de mediadores, com o ambiente físico e também com os seres humanos, com a finalidade de satisfazer suas necessidades e com o intuito de atingir maior autonomia.

Segundo a MJE3, filiada a um partido político, ela o fez "[...] para poder participar mais de discussões políticas, poder me inteirar melhor nos assuntos acerca da conjuntura nacional, regional, estadual e mundial". Questionamos-lhe se a filiação a um partido político é obrigatória quando se passa a fazer parte de um coletivo. Segundo ela, que faz parte de um coletivo feminista, isso não é tido como uma obrigação, “[...] mas você acaba se filiando para participar mais das coisas".

Segundo o HJE1, não é filiado a nenhum partido político, mas ao coletivo da União da Juventude Comunista: 
[...] não temos uma política de filiação, a gente considera filiação em termos apenas jurídico, nos considerando como militantes. Então, para fazer parte, você tem que ser militante e não simplesmente se filiar. O que me levou a me organizar nesse coletivo foi a necessidade que eu sentia em construir uma luta que não fosse sozinho, que fosse organizada e que tivesse em rumos nacionais, que eu encontrasse amparo em uma linha política, que eu considerasse acertada, que construísse isso também.

Para o HJE2, que é filiado a um partido político, ele acredita que a filiação “[...] é uma ferramenta necessária à luta das massas e da classe trabalhadora, apesar de suas contradições." Além disso, que faz parte do "[...] Coletivo ParaTodxs de militância de juventude e me aproximei do coletivo devido a ser o movimento de juventude vinculado a minha corrente interna no Partido."

É possível vislumbrar nestes casos, a perspectiva de que a territorialidade é fundamentalmente dinâmica, ou seja, nunca é fixa e estável, devendo ser entendida em sua lógica processual como um conjunto em constante mudança das relações de um indivíduo e/ou grupo social com a alteridade e a exterioridade.

Para Albagli $(2004,27)$, a territorialidade pode ser compreendida tanto no nível individual quanto no coletivo, em que “[...] no nível individual, territorialidade refere-se ao espaço pessoal imediato, que em muitos contextos culturais é considerado um espaço inviolável" e, no coletivo "a territorialidade torna-se também um meio de regular as interações sociais e reforçar a identidade do grupo ou comunidade".

Podemos considerar que os novíssimos movimentos sociais independem do associativismo a determinada instituição, uma vez que as formas com que as mobilizações ocorrem são distintas, dando-se nos espaços virtuais e/ou físicos.

Além disso, que a associação a partidos políticos e/ou coletivos, nos parece estar próximo muito mais à necessidade desses jovens, ao longo de suas trajetórias políticas, se organizarem em torno de pautas específicas a estas instituições, como as estudantis, por exemplo. Como foi possível verificar, inclusive, nas entrevistas, em que os jovens ao mencionarem sobre suas trajetórias políticas, suas associações a determinados partidos políticos e/ou coletivos não se deu desde o início das participações em movimentos sociais. O que nos leva a, de certa forma, não excluir, seguindo as linhas teóricas adotadas a esta pesquisa, a afirmação de que o associativismo institucional independe para a mobilização e, portanto, confirmando mais uma das características dos novíssimos movimentos sociais.

Também nos interessou compreender um pouco mais sobre o que mudou na forma como convivem consigo mesmos e com seus entornos depois de terem iniciado suas trajetórias em movimentos sociais. Considera-se importante essas ponderações a fim de compreender suas continuidades e/ou rupturas com questões que lhes motivaram, inicialmente, a mobilizarem-se. Cabendo, portanto, a especificação de que não se tratam de generalizações no que tange as vivências desses jovens, mas às experiências de vida individuais. Para a MJE2:

Tudo para ser bem sincera! Eu tive uma experiência muito incomum, que nunca tinha sequer passado pela minha cabeça, com os movimentos sociais. Por ter ocupado a minha escola e por ter participado do Primavera Secundarista, fui convidada um dia a fazer uma fala na Assembleia 
Legislativa do Paraná [...] e ela teve uma grande proporção que de fato mudou a minha vida e mudou tudo, mudou as minhas oportunidades, mudou a minha interpretação e ofereceu muita coisa que eu nunca teria tido, me levou a muitos lugares, me fez conhecer pessoas, me fez conhecer movimentos, enfim, ter uma experiência muito rica. [...] É por conta desses movimentos que transformou o que é hoje a minha militância, meu ativismo. Hoje eu participo de uma estrutura partidária, tenho muito orgulho disso [...] e isso não significa que eu não vejo inúmeros problemas e não faça inúmeras críticas, mas entendo que os partidos são uma representação política, mais fiel e mais responsável, concreta e organizada [...].

\section{Para a MJE3:}

Sim, totalmente, a minha visão de mundo ficou muito mais ampla e clara. Quando você participa de movimentos sociais você conhece todos os tipos de pessoas, que tem todos os tipos de vivências. Essa troca de experiências engrandece muito o ser humano, você aprende que não é somente o seu meio social que existe, um mundo inteiro está lá fora. Você aprende que nem todo mundo tem as mesmas oportunidades que você e que não é culpa delas isso. Você aprende a não ser egoísta e olhar para o outro, aprendemos a ter a mente e o coração mais abertos, aprende que se todos derem as mãos o mundo muda.

Para o HJE1:

[...] eu era muito inconsequente e ter me organizado, inclusive, fez com eu tivesse mais disciplina, mais consciência dos meus atos, que conseguisse construir inclusive uma unidade de ação em minhas atividades, pensar politicamente todas as coisas, pensar de fato como funcionam as coisas. Ter participado me criou muita experiência política, me ajudou muito.

O HJE2, também trazendo elementos afirmados pelos demais entrevistados, complementa indicando a existência de contradições no interior dos próprios movimentos sociais, coletivos e/ou partidos políticos. É possível, inclusive, identificar a sua luta pela manutenção da identidade, um dos elementos característicos da territorialidade, como segue:

Tudo se modifica. Não é minha intenção romantizar demais a participação nos movimentos sociais, pois há, dentro destes, suas contradições, sobretudo pelas disputas internas que se delineiam pelo poder e pelo controle de narrativas, mas a partir do momento em que abrimos nossa percepção para a coletividade, todas as dimensões sociais que nos atravessam são modificadas. Por exemplo, ser LGBT e atuar contra a LGBTfobia num contexto familiar LGBTfóbico gera, sem dúvidas, uma diferenciação não só nas formas de enxergar, mas também de como minha atuação perante a sociedade deve se dar, sendo a família um ambiente de aprendizado sobre aquilo que a gente concorda e discorda e sobre como lidar com isto. É um ambiente experimental. Os entendimentos sobre direitos e o aprofundamento nas lutas sociais e combate à desigualdade, nos faz assumir uma postura de enfrentamento em todos os espaços, nos fazendo enxergar com mais facilidade aquilo que, ideologicamente e pragmaticamente é executado nos espaços, e que discordamos. [...] Acrescento que não somente enxergamos as coisas sob uma nova ótica, mas também nos enxergamos de outra forma [...].

Nas afirmativas dos entrevistados quando lhes questionamos sobre o que diriam para si mesmos se pudessem voltar ao tempo, no início de sua militância, para a MJE2: 
Eu acho que eu falaria para eu manter muita calma, para eu centrar muito no que é prioridade para mim também [...] e para fazer mais as coisas, para me engajar mesmo, para não desistir [...]. Mas eu não me arrependo de maneira alguma e se eu pudesse começar tudo de novo, eu começaria e não pretenderia deixar nada para trás.

A MJE3, MJE4, MJE5, o HJE2 e o HJE3, reforçam a relação entre sujeitos, objetos e mediadores, como tratamos acima. A MJE3: "Falaria para bater menos boca com quem não quer ouvir e conversar com quem realmente quer discutir e debater sobre o assunto." A MJE4:

Comece mais cedo. Tenha fé em você mesma, independente do que te falarem. Esses sonhos lindos de uma menina podem virar os sonhos lindos de toda uma juventude. Você é gigante e pode levar milhares de mentes e corações com você.

A MJE5 diria a si mesma: "Calma, respira vem bomba pela frente mais vai vale a pena!". O HJEl: "Se eu pudesse voltar no tempo eu diria 'se organize, conheça a União da Juventude Comunista e construa ela". O HJE2: “Falaria que este é o caminho." E o HJE3: "Eu diria a mim mesmo que no fim tudo valerá a pena, a luta é difícil, mas é por um bem maior."

Considera-se que ao fazer um esforço para compreender um pouco mais sobre as trajetórias de vida dos 123 jovens pesquisados, mesmo que aqui não tenhamos trazido as falas de todos, é possível afirmar, sem romantizar, mas levando em consideração a lógica do que motiva os movimentos sociais, que eles vão persistir a lutar, debater, evoluir e a se dissolver em suas condições de existência, assim como ocorreu com todos os movimentos sociais da história. E isso porque a única demanda relevante para se avaliar a acepção de um movimento social é a produtividade histórica e social de sua prática e seu efeito sobre os participantes enquanto sujeitos e sobre a sociedade que busca transformar.

Concorda-se que é muito cedo para ajuizar o resultado final desses movimentos, embora já possamos indicar que regimes se transformaram, instituições foram desafiadas e a confiança no capitalismo financeiro global triunfante foi abalada, provavelmente de modo irreversível, na mente da maioria das pessoas (Castells 2013).

Se a lógica de continuidade da luta está nos discursos proferidos pelos investigados a esta pesquisa, então é possível vislumbrar que, em meio a um contexto glocal, com jovens imersos em espaços de participação físicos e também virtuais e que os levam para diversas partes do mundo, que lhes permitem compartilhar informações, conhecimentos e anseios com milhares de pessoas, então o mundo continuará a reivindicar por seus direitos.

E ao refletirmos sobre os novíssimos movimentos sociais, é possível enxergá-los imbuídos de territorialidades, uma vez que a consideramos enquanto referente às relações entre um indivíduo ou grupo social e seu meio de alusão, manifestando-se nas múltiplas escalas geográficas - uma localidade, uma região ou um país - e anunciando um sentimento de pertencimento e um modo de operar no âmbito de um dado espaço geográfico (Albagli 2004). 
E quando pensamos em coletividade inclusive como característica da territorialidade, questão verificada nos trabalhos de campo, pode-se indicar que:

A territorialidade é um fenômeno social que envolve indivíduos que fazem parte do mesmo grupo social e de grupos distintos. Nas territorialidades, há continuidades e descontinuidades no tempo e no espaço; as territorialidades estão intimamente ligadas a cada lugar: elas dão-lhe identidades e são influenciadas pelas condições históricas e geográficas de cada lugar (Saquet e Sposito 2009, 88).

Para além, a territorialidade, no singular, remete algo extremamente abstrato, o que faz de qualquer território um território, ou seja, as relações de poder espacialmente demarcadas e agindo sobre um substrato referencial, e ainda ao sentimento de "pertencer àquilo que nos pertence".

Por fim, vivemos um momento das simultaneidades, dos cruzamentos, das relações .próximas e, especialmente das distantes. Época das redes e das múltiplas relações e identidades.

\section{Conclusões}

Neste trabalho, propôs-se discutir sobre a existência de uma territorialidade política dos jovens nos novíssimos movimentos sociais e, portanto, considera-se que esta encontrase implícita e explicitamente, seja de forma autônoma e/ou coletiva nos jovens aqui pesquisados, sob a forma de engajamento e de luta em espaços físicos e/ou virtuais, uma vez que a territorialidade é eminentemente relacional.

Nessas relações "[...] operam a intercomunicação dos sujeitos pelos códigos e símbolos compartilhados, pelas causas que os animam, pelas relações de poder (ou contrapoder) e toda sorte de dinâmicas afetivas." E é na experiência da territorialidade que estão contidos exercícios afetivos sobre o espaço e sobre os objetos e eventos nele arrolados. "Esse exercício afetivo não é apenas expressão emocional do particular e do privado, mas é um estímulo-reação para a objetividade de vida, manifestada nos processos de luta e contestação das estruturas de poder e contrariedades" (Santos e Cunha 2018, 42).

E ainda, trata-se de um fenômeno social que abarca indivíduos que fazem parte do mesmo grupo social e de grupos distintos, que creem que a luta, da forma que seja, lhes fornece elementos de tessitura, relacionado ao que lhes confere o motivo de ser e o significado das coisas, que os tornam interdependentes, em que estão imbricadas relações de poder.

A territorialidade enquanto o "lado vivido" do "lado atuante" do poder, em que é nessa base que ela captura as interseções entre sociedade, espaço e poder, abarcando que ela é o oculto, a estrutura dissimulada do cotidiano, como explicita Yilmaz (2018), como sendo uma ação social e racional que propositalmente é realizada por indivíduos e organizações coletivas. Neste sentido, que os movimentos sociais são ações que desenvolvem relações complexas e diversificadas sejam em seu interior ou no que está externo a ele. 
E a territorialidade política dos jovens está neste movimento de lado vivido e atuante do poder e do contrapoder, capturando o oculto nas relações entre sociedade, espaço, poder e indivíduos, nas suas individualidades e/ou coletividades. A territorialidade política dos jovens está em pertencer, existir e resistir!

\section{Bibliografía}

Albagli, Sarita. 2004. Território e Territorialidade. In: Lages, Vinícius, Christiano Braga, Gustavo Morelli (orgs.). Territórios em movimento: cultura e identidade como estratégia de inserção competitiva. Rio de Janeiro: Relumes Dumará. Brasília, DF: SEBRAE.

Alonso, Angela. 2009. As teorias dos movimentos sociais: um balanço do debate. Lua Nova, São Paulo, 76: 49-86, 2009. Disponível em: https://www.scielo.br/pdf/ln/n76/n76a03.pdf. Acesso em: 1 jun. 2019.

Álvarez-Benavides, Antonio. 2016. Juventud sin futuro: precariedad, subjetividad y activismo. Disponível em: http://www.fessociologia.com/files/congress/12/papers/2889.pdf. Acesso em: 2 maio 2019.

Augé, Marc. 1994. Le sens des autres. Actualité de l'anthropologie. Paris: Fayard.

Betancor, Gomer, Roberto Cilleros. 2013. "El 15M en retrospectiva. Análisis de un estudio cualitativo de opinión pública y de los activistas". Anuari del Conflicte Social 2013. Barcelona: UB. Disponível em:

http://revistes.ub.edu/index.php/ACS/article/view/10337. Acesso em: 3 mar. 2019.

Cassab, Clarice. 201 1. "Contribuição à construção das categorias jovem e juventtude: uma introdução. Locus: Revista de História, Juiz de Fora, 17(2):145-159. Disponível em: http://www.ufjf.br/nugea/files/2010/09/Locus.pdf. Acesso em: 07 de maio de 2018.

Castells, Manuel. 2013. Redes de indignação e esperança: movimentos sociais na era da Internet. Rio de Janeiro: Jorge Zahar.

Castells, Manuel. 2018. O poder da Identidade: a era da informação. V.2. 9a edição. São Paulo/Rio de Janeiro: Paz e Terra.

Estanque, Elísio. 2014. "Rebeliões de classe média? Precariedade e movimentos sociais em Portugal e no Brasil (2011-2013)". Revista Crítica de Ciências Sociais [Online]. Coimbra, 103: 53-80. Disponível em: http://rccs.revues.org/5540. Acesso em: 24 de abr. de 2019.

Feixa, Carles. 2006. De jóvenes, bandas y tribos. $3^{\text {a }}$ edición actualizada. Barcelona: Editorial Ariel, S. A.

Feixa, Carles, Lara Pires Weissböck. 2019. Da Geração@a Geração Blockchain: a juventude na era postdigital. Textura - Revista de Educação e Letras. Universidade Luterana do Brasil 21(47). Disponível em:

http://www.periodicos.ulbra.br/index.php/txra/article/view/5110.Acesso em: $10 \mathrm{de}$ set. de 2019.

Gohn, Maria da Glória. 1997. Teorias dos movimentos sociais: paradigmas clássicos e contemporâneos. São Paulo: Loyola.

Gohn, Maria da Gloria. 2018. Manifestações e protestos no Brasil: Correntes e contracorrentes 
na atualidade (Questões da nossa época). Cortez Editora. Edição do Kindle.

Juris, Jeffrey S., Inés Pereira, Carles Feixa. 2012. La globalización alternativa y los 'novísimos' movimientos sociales. Revista del Centro de Investigación. Universidad La Salle, 10(37):23-39. Universidad La Salle Distrito Federal, México.

Keniston, Kenneth. 2008. "Juventud: una nueva etapa de la vida". En Teorías sobre la juventud: las miradas de los clásicos, editado por José Antonio Pérez Islas, Mónica Valdez Gonzáles. (Coords.), 249-269. México: Miguel Angel Porrua. Grupo Editorial. Koleni, Maryam. 2016. Causality, power and advantages of social movements. Disponível em:

https://www.academia.edu/22482808/CAUSALITY POWER AND ADVANTAGES O F SOCIAL MOVEMENTS Social Movements Causality Power and Advantages?e mail work card=interaction_paper. Acesso em: 21 de nov. de 2019.

Nilan, Pam, Carles Feixa. 2014. “¿Una juventud global? Identidades híbridas, mundos plurales.En De la Generación@a la \#Generación:La juventud en la era digital, editador por Carles Feixa, 57-121. Barcelona: Ned Ediciones. Edição do Kindle.

Perez, Olívia Cristina, Bruno Mello Souza. 2017. Velhos, novos ou novíssimos movimentos sociais? As pautas e práticas dos coletivos. $41^{\circ}$ ENCONTRO ANUAL DA ANPOCS - GT1 1 Entre as Ruas e os Gabinetes: institucionalização e contestação nos movimentos sociais. Caxambú/MG. Disponível em: http://anpocs.com/index.php/encontros/papers/41-encontro-anual-da-anpocs/gt30/gt11-15/10696-velhos-novos-ou-novissimos-movimentos-sociais-as-pautas-epraticas-dos-coletivos/file. Acesso em: 20 de nov. de 2018.

Raffestin, Claude. 1993. Por uma geografia do poder. Tradução de Maria Cecília França. São Paulo: Ática.

Raffestin, Claude. 2012. "Space, territory, and territoriality". Environment and Planning D: Society and Space 30:121-141. Disponível em:

https://journals.sagepub.com/doi/10.1068/d21311. Acesso em: 4 de dez. de 2019.

Reguillo, Rosana. 2017. Paisajes insurrectos: Jóvenes, redes y revueltas en el otoño civilizatorio. España: NED Ediciones.

Sack, Robert David. 1986. Territorialidade humana:teoria e história. Cambridge: Cambridge University Press.

Santos, Gustavo, Cunha Maria das Graças. 2018. “As Territorialidades Insurgentes do Gigante Desperto: Jornadas de Junho de 2013 no Brasil e suas Dinâmicas Territoriais". Revista Do Departamento De Geografia, 35, 37-48.

Saquet, Marcos Aurelio. 2015. Por uma geografía das territorialidades e das temporalidades: uma concepção multidimensional voltada para a cooperação e para o desenvolvimento territorial. Rio de Janeiro: Consequências.

Saquet, Marcos Aurelio, Eliseu Savério Sposito. 2009. "Apresentação". En Territórios e territorialidades: teorias, processos e conflitos, editado por, Marcos Aurelio Saquet y Eliseu Savério Sposito. São Paulo: UNESP.

Schindler, Norbert. 1995. "Los guardianes del desorden: rituales de la cultura juvenil en los albores de la era moderna". p. 303-364. En Historia de los jóvenes: I De la antigüedad a la edad moderna, editado por Giovanni Levi y Jean-Claude Schmitt, 303-364. Paris: 
Édition du Sueli.

Soeiro, José. 2014. "Da Geração à Rasca ao Que se Lixe a Troika. Portugal no novo ciclo internacional de protesto". Sociologia, Revista da Faculdade de Letras da Universidade do Porto XXVIII: 55-79.

Yilmaz, Samet. 2018. Human Territoriality: a spatial control strategy. Alternatif Politika, 10 (2): 131-155.

(c) Copyright: Lara Pires Weissbock y Márcia da Silva, 2021

(c) Copyright: Scripta Nova, 2021.

Ficha bibliográfica:

PIRES WEISSBOCK; DA SILVA, Márcia. Os novíssimos movimentos sociais e as territorialidades políticas juvenis: pertencer, existir e resistir!. Scripta Nova. Revista Electrónica de Geografía y Ciencias Sociales. Barcelona: Universitat de Barcelona, vol. 25, Núm. 4 (2021), p. 73-96 [ISSN: 1138-9788]

DOI: $10.1344 / s n 2021.25 .32047$ 
